\title{
Patterns of Interaction on Peer Feedback: Pair Dynamics in Developing Students' Writing Skills
}

\author{
Sirikarn Kuyyogsuy ${ }^{1}$ \\ ${ }^{1}$ Graduate School of Human Sciences, Assumption University of Thailand, Thailand \\ Correspondence: Sirikarn Kuyyogsuy, Graduate School of Human Sciences, Assumption University, Thailand 10240. \\ E-mail: gse.abac@gmail.com
}

Received: May 8, 2018

doi:10.5430/ijhe.v8n3p191
Accepted: May 31, 2019

Online Published: June 3, 2019

\begin{abstract}
The study investigated students' patterns of interaction and their viewpoints toward incorporating peer feedback in L2 writing class, making use of a video stimulated recall (VSR) interview and the compositions. Data were analyzed qualitatively; two groups of six students with mixed English proficiency were analyzed in terms of the language-related episodes (LREs). The participants of the study were 21 undergraduate students, majoring in English in a university in the three southernmost border provinces of Thailand. For data analysis, peer dialogues were recoded, transcribed and coded to identify students' patterns of interactions in terms of collaborative, expert/novice, dominant/dominant and dominant/passive patterns, based on Storch's (2002) scheme. Moreover, the findings revealed that the students' English proficiency level did not influence the LREs and their writing ability. Additionally, students' writing performance was improved in the identified patterns of the collaborative and expert/novice instances. Specifically, students perceived the writing process, developed affective strategies, reinforced their critical thinking ability and enhanced their social interaction skills. Besides, it encouraged them to become more effectively autonomous learners. Hence, peer feedback should be implemented in L2 writing.
\end{abstract}

Keywords: peer feedback, pattern of interaction, L2 writing, collaborative dialogue

\section{Introduction}

Peer feedback has been considered as an imperative feedback delivery system in process-based second language writing classes, and it has been widely defined as an effective method to support teachers for students' writing competence (Rollinson, 2005). Several studies have strongly insisted the potential of conducting peer feedback toward the development of ESL/EFL writing contexts and students' language learning (Hyland and Hyland, 2006; Lam, 2010; Nguyen, 2016). Thus, peer feedback has become a popular area for research in L2 writing context. Peer feedback is one aspect of peer assistance and collaborative learning; furthermore, it has always been adopted into the approach of writing process for one's draft revision at different levels in education and perceived as an interactive learning process that learners can be involved in dialogues associated with the performance and standard (Liu and Carless, 2006). Moreover, one prominent feature of peer feedback is that it focuses on the provision of fruitful responses without the judgment or evaluation of the written task (Chang, 2016). Hence, peer feedback plays a pivotal role in L2 writing, and it has a great deal of advantages and positive effects on the improvement of students' writing. Likewise, it empowers students by practicing their assessment skills to boost confidence, decreases their writing anxiety, and helps them become more active and independent (Tsui and Ngo, 2000). Additionally, it helps reinforce their critical thinking and raises self-awareness of effective writing abilities by offering critical and constructive feedback as Rollinson (2005) claimed. Particularly, a peer-involved activity helps encourage their self-confidence and self-motivation in writing. Furthermore, it supports cooperative, collaborative learning and social interactions, which helps support students to share ideas with each other, develops peer trust, and makes them responsible for the community in completing their written tasks (Olsen and Kagan, 1992; Oxford, 1997, as cited in Kunwongse, 2013). As mentioned earlier, peer feedback has the potential in improving L2 learners' writing.

According to the social interactionist view, learning is defined as a social act and not as "a solitary demonstration of individual knowledge" (Robinson 2014, p. 1), in which language learners become involved in different types of interactions. Multiple meanings create multiple learning outcomes. In the context, the teacher is in charge of his/her role as a facilitator more than as an instructor in the act of providing opportunities for learners to interact in meaningful and authentic ways; such as, peer feedback that advocates a problem-solving activity. Vygotsky's (1978) 
sociocultural theory also places emphasis on the potential of incorporating peer feedback by exploiting that. On the other hand, participants interact with each other in meaningful ways, so they get involved in meaning negotiation and hypotheses-testing in second language (Ahmadian and Tajabadi, 2017). Thus, peer feedback is reinforced by the communicative language teaching method that provides authentic communications to the students.

With respect to the theoretical aspect of collaborative learning, this implies that feedback provided by peers has immense potential to be associated with learning, which is considered a socially and collectively constructed activity. In addition, peer feedback can advocate peer interaction and collaboration, and it also produces "a facilitative socio-interactive environment in which L2 learners receive social support and scaffolding from peers" (Hu and Lam, 2010, p. 373). Moreover, students' motives can be based on the perspectives of a theoretical activity, which exploits that 'human activities are driven by motives and are realized in goal-directed actions performed under specific conditions' (Zhu and Michell, 2012, p. 365). Additionally, the significant role that motives provide an explanation regarding humans' practices or behavior motivate the activities; therefore, peer feedback has been determined to be an activity driven through students' motives (Jin and Zhu, 2010).

Referring to collaborative dialogue, this is defined as 'dialogue in which speakers are engaged in problem-solving and knowledge-building' (Swain, 2000). The dialogue provides learning with more chances in co-constructing a complex linguistic structure for the students. However, recent studies have confirmed peer-peer collaborative dialogue to be a crucial issue of the L2 learning process (Swain et al., 2002). Hence, this found that proficiency differences have been considered as an influential factor of natural peer-peer interaction. Moreover, the nature of interaction during peer feedback is limited in exploring how learners' patterns of interaction in peer feedback in the collaborative, dominant/dominant, dominant/ passive, expert/novice ones are mainly caused by the influence of the students' motives for the participation on peer feedback as Storch (2004) stated.

A few studies revealing this issue investigated the interaction of pairs involving the different proficiency of the learners. Therefore, this present study was conducted to gain an insight into this underexplored aspect. It was also confirmed by Roberson's (2014) study, which found that one of the characteristics of peer feedback that has been "under-examined in relation to the outcomes of peer response is the social positioning of peer responders" (ibid, p. 3). As mentioned above, the researcher believes that peer feedback plays an imperative role in motivating students' participation in L2 writing because of its fruitful potential in developing their writing competence. Accordingly, in the study, there was a need to explore students' patterns of interaction on using peer feedback in an L2 writing class, which was conducted at the EFL tertiary level in the three southernmost border provinces of Thailand.

\section{Literature Review}

Peer feedback in L2 writing is deeply rooted in many theoretical frameworks with different disciplines, which cover writing, second language acquisition (SLA), applied linguistics, education, cognitive and psycholinguistic fields. Moreover, these theories include the process writing theory, collaborative learning theory, interactionist learning theory in SLA and the cognitive and psycholinguistic fields, as well as sociocultural theory (Storch, 2002, 2004; Villamil and Guerrero, 2006; Zhu and Mitchell, 2012, as cited in Yu and Lee, 2016). Moreover, Vygotsky (1978) highlights the importance of meaning negotiation among learners in increasing their cognitive skills and enhancing their social interaction. Additionally, peer feedback puts emphasis on the importance of the social context and social interaction in establishing a deeper understanding of the learning process (Halliday, 1978; Berkenkotter and Huckin, 1995, Paltridge, 2004). This means that learners can construct their knowledge in a social context by taking part in a problem-solving activity, which helps support their critical thinking abilities and creativity. To elaborate clearly, they are engaged in activities and actual situations that help them to gain knowledge through a meaningful dialogue and can apply it to new situations. Likewise, this provides learners with more chances to develop their learning in a conducive circumstance (Farrah, 2012). As mentioned earlier, peer feedback offers learners opportunities to participate in a peer-engaged activity through meaningful dialogue and increase their interaction to improve their language learning more effectively.

Peer feedback is also known by several terms: peer critique, peer review, peer revision, peer response, peer editing and peer evaluation (Mangelsdorf, 1992). Moreover, peer feedback can be provided in the written or oral mode, or synchronous or asynchronous mode. Many studies by various scholars have revealed that peer feedback has the positive effects of improving students' writing in the L2 context (Hu and Lam, 2010; Min, 2016; Khalil; 2018). For example, peer feedback offers students multiple sources of constructive feedback; the recursive process of peer feedback increases their awareness, builds their confidence, motivates them in active engagement, enhances their critical thinking ability, and supports the social dimension through working collaboratively (Hirose, 2008). In addition, peer feedback raises learners' awareness of the role of technological applications in the teaching and 
learning process through the roles of university students and teachers as Allharbi (2019) addressed. Furthermore, it is an intricate activity, which reinforces affective, cognitive, sociocultural and linguistic perspectives to learners (Liu and Hansen, 2002). Brusa and Harutyunyan (2019) added that peer feedback, for its part, is a learning tool based on the sociocultural approach. It allows students to achieve higher levels of autonomy and critical thinking based on Vygotsky's sociocultural theory in relation to increasing their communicative competence. As a consequence, in integrating peer feedback in educational classroom settings, teachers need to provide explicit guidance with a well-prepared teaching performance to make students gain the fruitful benefits of conducting peer feedback.

\subsection{Collaborative Dialogue and Patterns of Interaction in Sociocultural Theory}

In the sociocultural perspective of learning, collaborative dialogue and interactional dynamics are believed to be the core of language acquisition. Collaborative dialogue is a source of L2 learning and development, and it is a way that mediates L2 learning and development. In addition, the type of dialogue is extended from the output hypothesis in which "speakers are engaged in joint problem-solving and knowledge building" (Swain, 2000, p. 102). Moreover, learning is mediated by symbolic tools and language being grounded on the sociocultural theory of Vygotsky (1978). Learners can also develop their cognition to mediate their relationship with the world by using the necessary tools. However, to examine the concept of collaborative dialogue with the advantages for L2 learners, many studies used two key analytical tools of language-related episodes (LREs) and pair dynamics. Swain and Lapkin (2002) defined LREs as episodes where learners pay attention to language use engaging with the dialogue. Significantly, interaction as the key component of this theory takes a crucial role on mediating learning, and many studies have reported that some patterns of interaction, which vary across peer groups, have proved to be more conducive to L2 learning than those of others in the peer-peer collaborative dialogue by placing emphasis on L2 learning (Nelson and Murphy, 1993; Storch, 2001a, 2001b, 2002a, 2002b, as cited in Wantanabe and Swain, 2007). Therefore, this present study aimed to investigate students' patterns of interaction on peer feedback through collaborative dialogue in L2 writing.

\subsection{Language Proficiency and Peer Interaction}

The previous studies have explored the impact of the proficiency level which was aligned to the interactional characteristics with meaning negotiation by focusing on the form, pedagogy and patterns of interaction. Some of the earliest studies of students' roles with their proficiency level in the learning process have shown that the negotiation of meaning in peer interaction included mixed and matched proficiency. The findings revealed that the proficiency levels did not have an impact on the negotiation of meaning although the amount of negotiation was equal to the high and low level of the proficiency. However, the students with a mixed high and low proficiency level could be a result of an increase of the miscommunication along with giving more attention to resolving it as means of negotiation (Varonis, 1985, as cited in Zarei and Toluei, 2017). Recently, some research indicated the advantages toward the mixed proficiency grouping; for instance, Lee (2008) reported that on peer interaction, the frequency use of scaffolding behavior between high and low proficiency learners on peer interactions helped create some structures that they could not establish from their own ability. Moreover, the high proficiency learners assisted the less proficiency ones to generate the linguistic acquisitions on their compositions as Ohta (2000b) stated. Notably, little research has rigorously investigated peer interaction across the levels of students' proficiency (Leeser, 2004; Storch, 2002). Specifically, to gain more insight into this issue, the study made an attempt to explore the patterns of interaction on the mixed proficiency learners through conducting peer feedback in an EFL writing class.

\subsection{Patterns of Interaction on Peer Feedback}

With regards to peer feedback use in L2 writing, several studies highlighted that pair interactions and language learning in ways which could be helpful for understanding and developing students' social interaction ability of conducting peer feedback led to their written improvement, so using patterns of interaction could be adopted to describe the social dynamics of peer feedback (Ferris, 2003). With respect to exploring the pair dynamics in collaborative dialogues, especially in the current study, Storch's (2002a) patterns of interaction was adopted (refer to Figure 1). 


\section{High mutuality

\begin{tabular}{c|c} 
4. Expert/Novice & 1. Collaborative \\
Low equality & \\
\hline 3. Dominant/Passive & 2. Dominant/Dominant
\end{tabular} \\ Low mutuality}

Figure 1. Storch's (2002) patterns of interaction

Storch's (2002a) framework allows interaction researchers to explore the relational stances which students use during peer discussion that included four patterns. In the first pattern of collaboration, the participants help solve the problems to achieve the goal. The high mutuality of each engagement is exhibited on the written tasks while another issue of the collaborative pattern demonstrates the equality. This pattern reaches a consensus at the end. This means that the students participate in producing new ideas, and then show that they are sharing the control over the direction of the task by displaying a high degree of equality, which characterizes the collaborative pattern. The second pattern is 'dominant/dominant'; this episode illustrates the disputes which occur in peer interaction. The main point of argumentation is for the assessor and assessee not to accept each other's ideas. There are no statistics or information in supporting the statement, and each adopts his/her own view such that no consensus about whether to include statistics is reached. They are engaged in attempting to control the direction of the task, but are not willing to engage in the other's discussion. This pattern shows high equality but low mutuality, which characterizes the dominant-dominant pattern. For a dominant-passive pattern as the third episode, this illustrates one participant controls the direction of the task, and the other demonstrates little engagement. The reader believes in his/her answer without asking and listening to the student writer. Thus, the reader is not interested or does not try to let the other engage in the tasks. The writers are quite silent; he/she has little interaction. This episode displays low equality in controlling the direction of the interaction and low mutuality due to no evidence of engagement or collaboration. With regards to the last episode called the expert-novice pattern, one participant (expert) assumes responsibility for the direction of the interaction. The expert tries to let the novice engage in the activity of the problem-solving process whereas the novice is grateful for his/her assistance. As such, the novice makes few contributions during the interaction. This exhibits low equality while the expert appears to have high mutuality by actively engaging in the tasks. However, there remain some similar patterns; such as, in the dominant/passive and expert/novice patterns where one participant controls the direction of the task; therefore, these two patterns both show low equality while two patterns in the dimension of mutuality engages the assessor's suggestions in the pattern of expert/novice than that of the other. Furthermore, in order to better understand L2 learners' participation in undertaking a peer group activity, this study attempted to explore the nature of the pair interaction on peer feedback. This was determined as the roles that the assessors and the assessees adopt with the written tasks in the revision. Therefore, the student writers and group feedback activity was based on Storch's (2002a) framework in identifying the four patterns of interaction on peer feedback. The present study was conducted with an attempt to gain an insight into this underexplored area by making use of a more appreciative qualitative design and to capture students' viewpoints on the relevance of peer evaluation and the role it should play in their learning. Among the few studies reported to date, the research questions were focused on the students' patterns of interaction on peer feedback use and their viewpoints toward peer feedback in an attempt to develop their writing skills.

\section{Methodology}

\subsection{Research Design}

The study entirely utilized a qualitative design by investigating students' patterns of interaction on peer feedback in developing their writing ability. However, a percentage was only used to calculate the number of their patterns that they performed in the duration of doing peer group feedback.

\subsection{Subjects}

The study was carried out in the 2018 academic year. The subjects of the study were 21 third-year undergraduate students with majoring in English of Liberal Arts in a university in the three southernmost border provinces of Thailand. They all were requested to participate in conducting peer feedback in a writing class. They had already completed two years of English courses, which covered English Structure I, English Structure II, Writing 1 and 
Writing 2. As aforementioned, this implied that all the participants had adequate English writing proficiency to conduct a peer group activity.

\subsubsection{Context of the Study}

As part of the larger study about doing the peer-involved activity in L2 writing class, this study investigated the patterns of interaction of using peer feedback in the writing of 21 Thai EFL university students. In reference to the students' backgrounds, they were all Muslims and had graduated from private religious schools. Importantly, they spoke Pattani-Malay, which is a dialect in which Thai-Muslims use to communicate as their mother tongue. According to Thai government, all public schools and universities are required to use Thai language for mother tongue-based education in mediating. However, all students were allowed to use the L1 (dialect) while providing feedback in case that they could not explain about the intended meaning of the vocabulary, phrases or sentences to their peers.

\subsection{Research Tools}

\subsubsection{A Video Stimulated Recall (VSR) Interview}

A video stimulated recall (VSR) interview was used to answer the research objective. The data sources consisted of three research tools; namely, video recordings, a semi-structured interview and written drafts. All were used at the end of peer feedback session to examine their patterns of interaction in the duration of doing peer group discussion. To identify this, the researcher and the participants viewed the video together on their performance of doing peer feedback on their written drafts. Nonetheless, to explore the students' perceptions toward peer feedback, six students were interviewed about the practices and usefulness of incorporating peer feedback in a writing class, and the interview was recorded and then transcribed by the researcher.

\subsubsection{Validity and Reliability of the Instrument}

The interview questions of the patterns of interaction on peer feedback were administered by three experts in the field of English to judge its congruence between the objectives and the interview questions. Specifically, the rated interview questions were calculated for the index of item-objective-congruence (IOC) as suggested by Rovinelli and Hambleton (1977). Subsequently, the interview questions were adapted from the comments and recommendations. The results presented that the content analysis was at 0.87 for all eight items, and to ensure the reliability, the inter-rater reliability was tabulated by the Spearman's Rho correlation coefficient with a rating of 0.94 .

\subsection{Data Analysis}

The analysis investigated the students' patterns of interaction on utilizing peer feedback in an L2 writing class through peer dialogues. The researcher read the students' transcripts and noted the segments that seemed important for further understanding about how students shared the control over their direction of the peers' tasks. Additionally, how they were involved in each other's suggestions about the revisions based on Storch's (2002) framework. In so doing, the second coder and the researcher identified the patterns of interaction in the peer feedback by coding the transcripts for the LREs and analyzing them for the frequency and interactive aspects, which gathered the characteristics of each episode by employing Storch's classification. To elaborate, students' transcripts were adopted to provide an insight into how they had experienced the patterns of interaction in which they were engaged. Moreover, thematic content analysis was adopted by means of a semi-structured interview by interpreting the data analysis according to Creswell's (2012) methods of qualitative data analysis. Two groups of six students with proficiency differences were chosen to identify their patterns of interaction on peer feedback. The interview script was analyzed in an attempt to investigate the students' strategies in answering to the peers' written drafts including their attitudes toward what they had perceived in doing peer feedback. The peers' written drafts in two sessions were collected and analyzed by the researcher.

\subsection{Data Collection Procedures}

Before starting the writing course, peer feedback training was administered for approximately three weeks. To achieve this, the students were effectively trained how to conduct the writing strategy and peer feedback process; providing and receiving feedback. The following eight weeks, they were required to perform their written drafts by doing peer group feedback in class, and the two groups of students were requested to take part in an interview by using a VSR interview to reflect what they had learned after completing the peer feedback session.

\subsubsection{Peer Feedback Training}

Before the peer feedback session starts, writing teachers should focus on the aspects to implement peer feedback on how to effectively train students to provide qualified feedback to their peers. In the current study, the concept from 
Min's (2005) four-step procedure and Lam's (2010) peer feedback training were adopted. Besides the lesson plan was suitably applied and adapted as the objective of the study. In particular, intensive peer feedback training was divided into three stages, which covered the first three weeks in the course of writing.

Modeling Stage: Peer feedback training session starts with introducing the writing strategy and informing about the objectives of incorporating peer feedback toward the practices and usefulness in a writing class. Afterwards, the researcher shared the objectives of the peer feedback training in order to provide students with the sufficient revision ability to create their tasks by means of introducing and demonstrating peer feedback. This was done by a four-step procedure: clarifying, identifying, explaining and giving suggestions as well as employing peer feedback checklists and coding five types of errors with examples to the students.

Exploring Stage: Students were required to practice some exercises about the four-step procedure and five types of errors with the use of peer feedback checklists. This allowed students to practice and evaluate how well they understood about employing the peer feedback materials and applying them. Afterwards, they were requested to exchange their tasks with their partners including marking the peers' work and discussing their grammatical errors. Then, seven students were interviewed about their learning barriers, as well as the benefits and drawbacks of adopting peer feedback to clarify their misunderstanding.

Consciousness Raising Stage: Students were required to produce a paragraph of narrative writing of about 150 words and then conducted peer discussion. Each student was responsible for two roles in the group feedback. As the role of assessors, they provided their written comments to the student reader while the role of the student writers called assessees received comments with suggestions and edited the errors. Peer feedback took place naturally, and if the assessees disagreed with the peer correction, they could immediately ask for clarification and explanations from their peers. By doing so, students' grades in Writing 2 were adopted to divide them into a group of three students with the mixed ability levels for greater participation and better performance. In the study, the approach of the writing process consisted of planning, drafting, evaluating, interactive back-feedback, reviewing and revising stages adapted from Flower and Hayes (1981), Kim (2005), and White and Arndt's (1991) conceptual framework.

\section{Results and Discussion}

\subsection{Students' Patterns of Interaction on Peer Feedback in L2 Writing}

The recorded peer discussion was transcribed by the researcher according to the transcription symbols provided in Table 1. Subsequently, as with similar research done in this field (Storch, 2007; Zheng, 2012; Robinson, 2014; Moussa and Azar, 2017), the transcripts were divided into episodes (refer to Appendix A). Based on the objectives of the study, two groups of six students was chosen to identify the patterns of interaction in the pair talk while they were conducting a peer feedback discussion in the genre of narrative writing on the topic of "My Bad Dream". The following four patterns of interaction were provided and analyzed the examples of the episodes that were coded. Each pattern was related to mutuality and equality, which was highlighted with a more in-depth discussion of the features of each pattern of interaction. The findings showed that among the four patterns, students improved their writing skill through the collaborative and expert/novice patterns. In total, six pairs with 48 patterns between the assessors and the assessees were identified (refer to Table 1). 
Table 1. Patterns of the interaction roles for each transcript across the two sessions

\begin{tabular}{|c|c|c|c|c|c|}
\hline Broup & Pairs & Participants & Proficiency Level & Session 1 & Session 2 \\
\hline 1 & 2 & $\begin{array}{l}\text { A \& B } \\
\text { B \& A } \\
\text { A \& C } \\
\text { C \& A } \\
\text { B \& C } \\
C \& B\end{array}$ & $\begin{array}{l}\text { Intermediate - Low } \\
\text { Low-Intermediate } \\
\text { Intermediate-High } \\
\text { High - Intermediate } \\
\text { Low-High } \\
\text { High - Low }\end{array}$ & $\begin{array}{l}\text { W: Expert: Novice } \\
\text { R: Collaborative } \\
\text { W: Expert: Novice } \\
\text { R: Collaborative } \\
\text { W: Expert: Novice } \\
\text { R: Collaborative } \\
\text { W: Expert: Novice } \\
\text { R: Collaborative } \\
\text { W: Dominant: Passive } \\
\text { R: Collaborative } \\
\text { W: Expert: Novice } \\
\text { R: Collaborative }\end{array}$ & $\begin{array}{l}\text { W: Expert: Novice } \\
\text { R: Collaborative } \\
\text { W: Collaborative } \\
\text { R: Collaborative } \\
\text { W: Expert: Novice } \\
\text { R: Collaborative } \\
\text { W: Expert: Novice } \\
\text { R: Collaborative } \\
\text { W: Collaborative } \\
\text { R: Collaborative } \\
\text { W: Collaborative } \\
\text { R: Expert: Novice }\end{array}$ \\
\hline 2 & 1 & $\begin{array}{l}A \& B \\
B \& A \\
A \& C \\
C \& A \\
B \& C \\
C \& B\end{array}$ & $\begin{array}{l}\text { Intermediate - High } \\
\text { High-Intermediate } \\
\text { Intermediate-Low } \\
\text { Low-Intermediate } \\
\text { High-Low } \\
\text { Low-High }\end{array}$ & $\begin{array}{l}\text { W: Dominant: Passive } \\
\text { R: Expert: Novice } \\
\text { W: Expert: Novice } \\
\text { R: Collaborative } \\
\text { W: Collaborative } \\
\text { R: Expert: Novice } \\
\text { W: Collaborative } \\
\text { R: Expert: Novice } \\
\text { W: Dominant: Dominant } \\
\text { R: Expert: Novice } \\
\text { W: Dominant: Passive } \\
\text { R: Dominant: } \underline{\text { Passive }}\end{array}$ & $\begin{array}{l}\text { W: Dominant: Passive } \\
\text { R: Expert: Novice } \\
\text { W: Expert: Novice } \\
\text { R: Collaborative } \\
\text { W: Collaborative } \\
\text { R: Collaborative } \\
\text { W: Collaborative } \\
\text { R: Collaborative } \\
\text { W: Expert: Novice } \\
\text { R: Expert: Novice } \\
\text { W: Expert: Novice } \\
\text { R: Expert: } \text { Novice }\end{array}$ \\
\hline
\end{tabular}

Note: *All names are pseudonyms $(A-C)$.

* H-I-L stands for High-Intermediate-Low Proficiency Level.

$* R$ stands for reader/ assessor, and W stands for writer/ assessee.

As Table 1 presents, the findings illustrated that the pairs of students with different proficiency levels became involved in the various patterns of interaction. All six pairs fit within the patterns of interaction based on Storch's (2002) framework. From an analysis of the patterns of interaction, among all four patterns, the most common one was the collaborative $(45.83 \%)$ followed by expert/novice $(41.66 \%)$ then dominant/passive $(10.41 \%)$, and dominant/dominant $(2.08 \%)$ across two sessions, respectively. Five out of the six pairs eventually corresponded to the collaborative and expert/novice patterns; however, the fourth pair indicated the dominant/passive pattern that was a result of student writer A while her partner occupied the expert/novice instance. This was also in agreement with Robinson's (2014) study, which illustrated that the dialogues among the five pairs of the students were associated to the identified patterns and their second written drafts. Moreover, this revealed that the two patterns of collaborative and expert/novice led to better writing improvement; additionally, it conformed with Liu and Hansen's (2002) study, which found that collaboration among peer group members helped students acquire knowledge both linguistically and in their writing skills. Correspondingly, the findings of the interviews indicated that students' patterns of interaction on peer feedback were associated to their writing improvement and increased their interpersonal skills in the collaborative or expert/novice instance. More importantly, Storch (2004) revealed that students in the collaborative or expert-novice instances exploited their motives in learning and were inclined to 'seek to increase their understanding or competence' (p.474), while students' motives in the dominant/passive and dominant/dominant patterns that were aligned with productivity rather than the process of learning had a tendency to 'seek positive judgments on their performance' (p. 474). In addition, similar studies found that the collaborative and expert/novice 
patterns were immensely outstanding to students' writing improvement after conducting peer feedback (Storch, 2002; Zheng, 2012, as cited in Yu and Lee, 2016).

From the research, it was apparent that the students conducted peer feedback more efficiently by switching their roles among the two sessions. Overall, the findings also coincided with Storch's (2002) scheme in spite of having large proficiency differences within each pair. To illustrate, when more proficient and less proficient students became involved in the activity in order to solve linguistic problems, one represents either the expert/novice, dominant/dominant, or dominant/passive patterns of interaction owing to the differences of their proficiency. Moreover, it indicates that the higher and lower proficiency students could be provided with more opportunities for learning together and working collaboratively. Additionally, four students preferred to work with a partner who actively expressed their opinions, shared their ideas, and exchanged their experiences in the discussion. Furthermore, the collaborative pattern of interaction was considered as the social dimension, which could develop students socially and intellectually. With regards to the proficiency level, the findings indicated that the proficiency differences of the students were not a decisive factor affecting the nature of the peer interaction than co-constructed by the learners. This means that the relationships which students established and the roles that they employed had an impact on the interaction among peer group members.

The analysis of peers' written drafts revealed that all students focused on the paragraph structure in terms of the content and organization in the beginning when they provided peer correction including a few examples of peer discussion on grammar use; such as, articles, tenses, prepositions and punctuation. In addition, the findings indicated that most of the assessors were interestingly observed negotiating for more feedback provided by their peers on grammar accuracy. This implied that students felt that using grammar structure was their major problem for revision because they had much paid too much attention on providing grammar correctness instead of realizing using grammar accuracy. Thus, the restriction of giving feedback on grammar correction provided a few instances in peer interaction. However, this created chances for offering learning instances. Furthermore, there was an increasing tendency to focus on grammar accuracy, which served as the most crucial aspect to be revised according to the peer dialogues in doing peer discussion. Importantly, students received opportunities to focus on the features of the texts in the approach of the writing process; moreover, the recursive process of doing peer feedback was so imperative in developing their writing ability including increasing the self-editing skills. Consequently, this could be objected to engaging in peer group discussion which may support students to review their writing skills with advocating grammar accuracy. Nevertheless, although proficiency differences might coerce students to specific types of patterns, it obviously demonstrated that this finally did not affect their relationships in forming peer interaction. Samples of the four episodes as illustrated in the duration of discussing peers' assigned tasks are as follows:

\section{Excerpt 1. Collaborative pattern}

Peer B: I want to say that "there was a thief".

Peer C: Is this sentence correct?

Peer A: Check about using the noun ending. Is this correct? Were a thief.

Peer B: [5] Yes, it's a noun.

Peer A: Is this a noun? Peer C... What do you think about it? Um ... if I place "thief" behind the verb, will be "were a thief"?

Peer C: Really?

Peer B: Should it be a plural noun?

Peer A: Of course, you need to put " $s$ ".

Peer B: Um ... (satisfied).

Peer A: If it's a singular noun, it will be "was a thief". This position should place " $s$ " and use "were".

Peer C: That's right!

Peer A: How about "thief"? Do I have to put "s"? I need you to check this word in the dictionary.

Peer B: Ok! I have to examine the rules for the plural noun.

Peer A: I'm not sure; it may change "f" into "ves".

Peer B: Yeah! I found it. 
As illustrated above, the results revealed that the students adopted a collaborative pattern of interaction. They discussed alternative opinions while they were solving the problems with an attempt to reach a resolution. In the dialogue, they were discussing the grammar structure in the aspect of using noun, subject + verb agreement, as well as noun ending. In the issue of the noun, they focused on the part of speech by examining the word "thief". Afterwards, they repeated it and elaborated on other's suggestions about using subject + verb agreement with a singular and plural noun by editing "was/were" in the sentence. Moreover, they engaged critically and constructively with Peer A's suggestions. In the terms of the nature and focus areas of their comments, this indicated that students actively provided a revision-oriented comment for the explanation 'Of course, you need to put ( $s$ ).' in using the plural noun. Peer A with a higher efficiency acted as a student teacher, but she collaboratively encouraged Peer B in a positive discussion. This made Peer B dare to express her ideas with an attempt to respond to Peer A by joining the activity with the answer 'Should it be a plural noun?' and learn together by displaying positive feelings. However, although the way of giving feedback as a teaching style by asking questions to revise Peer B's English knowledge, her voice and language use was conducted in an appropriate and positive way to make Peer B appreciate her assistance and become involved in the peer group discussion. Eventually, they reached a consensus at the end by solving the problematic area of the grammar structure.

\section{Excerpt 2: Dominant-dominant pattern}

Peer B: Ok. For the first step, ((did you remember the teacher always emphasizes)) about the "main idea" in the paragraph structure?

Peer A: Here! A single sentence.

Peer C: No!

Peer B: No! It's not correct. It's not the main idea. The main idea must be written as a single sentence, but this is not a sentence; just a fragment.

Peer A: $\quad \ldots$ (unsatisfied).

In Excerpt 2, this episode illustrated an argument which takes place in the dominant-dominant pattern. From the peer talk, the students were discussing how to construct the main idea of the text. Obviously, each adopts his/her own view in offering feedback between the assessors and the assessee. However, among Peer B and Peer C's discussion, they rejected Peer A immediately without accepting Peer A's ideas, and Peer B attempted to control the direction of the work and referred to knowledge that she had obtained from the teacher while Peer C strongly refused to Peer A without any comments. Nevertheless, Peer A disagreed and objected to the peer editing by pointing to her answer. After that, Peer B strongly denied her again and identified the errors that she had produced. In contrast, Peer A did not accept the criticism as demonstrated by expressing her negative feelings. In composing the main idea of the paragraph, it seems that each is confident in his/her own answers with some disputation. This also indicates one of the dominant characteristics of the students' behavior through the negative reactions as Zheng (2012) reported. All of them contributed to the errors with little problem-solving and willingness to reach a consensus. Moreover, there was little negotiation between them, and Peer A's contribution was silence, which in turn she displayed her negative facial reactions, so this pattern was occupied by a moderate to high quality and moderate to low mutuality.

\section{Excerpt 3: Dominant-passive pattern}

Peer A: In addition, why did you put "to" and comma (,)?

Peer B: [I'm wrong; I misunderstood.]

Peer A: Yes.

Peer C: (laugh)

Peer B: In addition, there's no need to put "to".

Peer A: Yeah! Cutting off "to".

Peer C: Your handwriting must be elaborate; the reviewer will not feel confused with giving feedback.

In Excerpt 3, this pattern demonstrated the dominant-passive interaction. In the dialogue, students put emphasis on using transitions and/or connectors in describing the text without any information. Additionally, the problematic point of which they were mentioning was the writer's handwriting. From the peer talk, Peer A showed her confidence in applying transitions and/or connectors by giving the correct answer. According to Peer A and Peer C's utterances, it seemed that they hardly paid any attention to Peer B's feelings in the peer responses, which in turn they 
attempted to show their good ability while Peer B contributed very little to the task. However, although Peer B accepted their comments and was willing to edit the errors, the way of giving feedback by Peer A and Peer C did not make Peer B grateful for their assistance in participating in the talk, so it seemed that she felt more negative when receiving the comments on her handwriting.

\section{Excerpt 4: Expert/novice pattern}

Peer A: Ok! Peer B after I read your text, I really liked it very much because it sounds very interesting.

Peer C: Yes, I agree with Peer A. It's very good. Um ... the support is like the main idea.

Peer A: Anyway, what a pity! Peer B forgot to write the main idea of the text.

Peer C: Yes.

Peer B: How about this one?

Peer A: "I had both a good and bad dream in my life." Well! A single sentence ... If you mention this sentence as the main idea, remember you should underline it. The main idea of the sentence must be clear.

Peer C: Well! It should be written as the single sentence, not a compound and complex sentence if you are not sure of the grammar.

Peer B: Well! Alright.

Peer A: How about this sentence? [5] Peer B, do you know what's wrong with it? [5] You forgot to place (s) plural after 'dream'.

Peer B: Yeah.

Excerpt 4 presents the expert-novice interaction. In this dialogue, Peer A took the role as the director of the task while Peer B adopted the novice role in the interaction. It can be seen that the way of the peer interaction was marked by great mutuality with low equality. From the peer talk, Peer A and Peer C gave their compliments on Peer B's writing. "I really like it very much because it sounds very interesting, Yes, I agree with Peer A. It's very good it is very good.", respectively. This was their invitation to involve Peer B in the discussion by showing their positive feelings. Before providing feedback she asked for their ideas about how to construct the main idea with the correct grammar to revise her prior knowledge of the paragraph structure. While discussing, Peer A called Peer B many times to encourage her to respond or ask about what Peer B had thought. This showed that she intended to offer meaningful feedback to Peer B; likewise, Peer $\mathrm{C}$ gave a positive compliment in creating the main idea of the text. From their discourse, Peer B had little interaction in the discussion; however, she did appreciate their help by showing positive facial reactions and was willing to edit the errors from peer response.

\subsection{Students' Attitudes toward Incorporating Peer Feedback in Developing Their Writing}

The VSR interview was adopted to have a better understanding of the students' interactions while undertaking the peer feedback and their intended roles. In analyzing the data, thematic content analysis was employed through reading the answers from the interviews several times with an attempt to find key words or key concepts where themes were identified through transcription and coding (Creswell, 2012). The results of this study indicated that students had positive attitudes toward adopting peer feedback for improving their writing skills in the collaborative and expert/novice instances. There were five themes extracted from the data analysis: giving types of feedback, feedback expectations, voice and language use, the factors of participating in a peer-involved activity, and students' viewpoints toward doing peer feedback in L2 writing.

The first of the five themes that emerged from the data focused on the types of feedback that students received while doing the peer group feedback. The findings illustrated three types of feedback: direct, indirect, and oral. This indicated that students placed emphasis on the global aspects rather than local ones in the ways of focusing on the content and organization. However, based on the surface changes and text-based changes, these aspects revealed that many students corrected the grammatical mistakes with the surface changes, not meaning changes which brought new information into their tasks; such as, mechanics. In addition, in providing feedback by peers, this focuses on developing students' ideas and organizing the texts, and obtaining peers' positive compliments and useful recommendations that can encourage them to improve their writing. This also concurred with Sawaya and Yokyama (2013) who proved that students' writing ability could be developed in the aspects of the content and organization by means of peer editing. A moderate proficient student in the collaborative stance expressed: 
"In my opinion, peer interaction provided me with more chances in expressing opinions, sharing ideas, offering feedback, negotiating meaning, and collaborating to the final written drafts. Moreover, discussing with peers helped me think critically to deliver information into my assigned tasks. In the problematic area of grammar, I mostly obtained a common comment from peers, and importantly, peers' compliments encouraged me to make better subsequent written tasks"

Student B in Group 1

With regards to the expectations of feedback as the second theme, the overall findings illustrated that students regarded feedback expectations with more meaningful and correct feedback from peers through more specific grammatical areas by gaining clear comments. Additionally, students' writing competence could be developed in terms of the content and organization; however, grammatical accuracy on providing feedback is still needed from peers (Berger, 1999, as cited in Lei, 2017). In this regard, a student who had a high English ability in the dominant/dominant pattern mentioned:

"I think that I distrusted peer correction, and I needed more details on the specific grammatical errors. Anyway, I accepted that peer discussion helped me gain more ideas, and I wanted clear feedback. I expected to get instant feedback while discussing, so I preferred the teacher's feedback."

Student B in Group 2

Subsequently, the overall results of the third main theme displayed that students highlighted about the voice and language use affecting the patterns of interaction in the peer feedback. The findings revealed that students held a positive viewpoint toward peer feedback. This indicated that heterogeneous group feedback helped students improve their writing. Nevertheless, in correcting peers' tasks, they sometimes used Pattani-Malay language in clarifying the mistakes in an attempt to make peers understand more clearly. Additionally, having positive reactions are imperative to achieve conducting peer group feedback. Specifically, doing a peer-involved activity regularly creates confidence in commenting on peers' tasks; this increases students' credibility on their peers trust. Moreover, Grabe and Kaplan (1996, p. 379) mentioned that a peer-involved activity enhances students 'learning together', and peer discussion assists students to learn how to use language in responding to tasks. Furthermore, the use of the L1 in an L2 classroom helps support learners to work collaboratively on writing tasks during difficult cognitive activities due to the L1, which is considered as a cognitive tool necessary to make sense of the L2 learning process (Anton and Dicamilla, 1998, as cited in Swain and Watanabe, 2013). Additionally, Storch and Aldosari (2013) found that peer interaction encouraged students to focus on language use when the higher proficient and less proficient students worked in groups. The higher proficiency student can adopt the L1 to provide information in expressing the meanings of the words to the weaker students. As mentioned earlier, mixing proficiency differences may benefit lower proficiency students when they perform in all patterns except for the dominant/passive stance. Two students with efficiency differences gave their opinions as follows:

A student with a high English proficiency in the expert/novice pattern addressed:

“I think that the peer feedback process helped me to learn how to provide qualified feedback to the peers' tasks and to improve my written performance. Of course, I prepared myself in giving feedback with a well-prepared teaching performance. However, I used the Pattani-Malay language (L1) in expressing some word meanings in particular to peer group members. Moreover, I viewed that positive reactions were needed during interacting, and especially I always reflected on my actions to see my strengths and weaknesses through conducting peer group feedback."

Student $C$ in Group 2

A low proficiency learner who exploited the expert/novice patterns mentioned:

"Peer feedback is new, and it motivated me to the peer-involved activity. It was good for me to work together through heterogeneous group feedback, and importantly I got the correct answers from the peers, which in turn, I was reluctant to provide feedback on the grammatical mistakes on the peers' tasks. Likewise, I had little interaction to express my opinions; however, constant practice of doing feedback encouraged me to provide more ideas."

Student B in Group 2

With regards to the crucial factors in participating in the peer group activity, the overall findings of the four main subthemes showed the important factors which motivated students to conduct peer feedback. The findings showed that students felt challenged in improving their tasks with the peers, and importantly they needed to develop their writing ability. The roles of the students created their responsibilities for doing group feedback in the critique of the peers' tasks. In particular, peer feedback is a new writing activity, which motivates students in learning. This 
coincided with Allharbi's (2019) study, which reported that peer interaction assisted students to enhance their language learning including writing and grammar through the role of students as both a feedback giver and receiver. This implied that they shoulder much of their responsibilities in the peer group feedback in providing constructive and supportive feedback. More importantly, peer interaction is defined as cooperative and collaborative learning which helps students develop intrinsic motivation, physically and mentally, through sharing information and their attempts to achieve the tasks, to develop trust with their peers, and to be responsible for their duties in taking part in the peer-engaged activity (Frey and Fisher, 2010; Olsen and Kagan, 1992; Oxford, 1997; Palmer, 2007; Williams and Williams, 2012, as cited in Kunwonge, 2013). Consequently, students' perceptions about peer evaluation influence their study behavior and their methods to learning. For example, an intermediate proficiency learner who occupied the collaborative stance noted:

"In my point of view, when I got the topic from the teacher, the writing process suddenly came into my mind. I could generate various ideas like mind-mapping and conveyed messages into my written drafts. Importantly, discussing among my peers assisted me to develop my ideas with creativity, and the roles of the students motivated me to the peer-engaged activity by taking great responsibilities as a feedback giver and a feedback receiver".

Student A in Group 1

Finally, the last main theme involved students' views toward peer feedback. Overall, the findings presented that students held their positive viewpoints about using peer feedback. The findings indicated that peer feedback had the fruitful potential in improving students' written tasks, reinforcing their critical thinking ability, working into groups more collaboratively, increasing their confidence in providing feedback, and understanding more about the writing and peer feedback process. They also placed importance on peer feedback training to achieve doing a peer group activity, and the majority of the students agreed that peer feedback should be adopted in a writing class. This was similar to Khalil's (2018) study, which proved that peer feedback had the potential in increasing self-motivation and improving self-confidence in discussing. Furthermore, students who are well-trained in peer feedback can improve their performance (Min, 2005; Lam, 2010; Konwonse, 2013; Nguyen; 2016). A student with a high English proficiency in the expert/novice pattern pointed out:

"In my opinion, peer discussion enhanced me to increase the critical thinking ability, and importantly I could develop socially through working collaboratively. I was more confident in writing, and the peer feedback process helped me to be less dependent on the teacher, and I learned to solve linguistic problems through self-assessment more effectively. The tactics that I obtained from the peer feedback trainings were useful in developing my writing."

Student $C$ in Group 1

As can be concluded that the findings revealed that students had positive attitudes toward incorporating peer feedback in both developing their writing performance and associating their interpersonal relationship when they employed either a collaborative or expert/novice instance in giving and receiving feedback. However, although the findings of the study on the patterns of interaction provided more benefits of the collaborative and expert/novice patterns than the dominant/dominant and dominant/passive patterns, there are still a few studies in this area, which the findings may not be generalizable to L2 contexts. Importantly, the research in this issue only focused on developing students' written performance. Further research could be extended to other language components such as exploring the interference of the L1 and L2 in peer interaction, or the vocabulary acquisition including multiple sources of data such as classroom observation, discourse analysis, discussion, interviews and students' written drafts. However, in this study the L2 proficiency of the students adopted their grades that they obtained in the writing course previous semester; therefore, this may have an impact on some of the findings.

\section{Conclusion and Implications}

This study investigated students' patterns of interaction adopting Storch's (2002) classification, and their views toward the usefulness and practice of the use of peer feedback in L2 writing class. The results illustrated that the collaborative and expert/novice patterns were the most frequently identified ones, and both were crucially associated with their better writing performance. In addition, the collaborative and expert/novice patterns were marked as providing great significance in stimulating the students to participate in the activity. In contrast, the dominant/passive and dominant/dominant patterns did not stimulate them to the activity for revisions. Besides, students develop themselves through mutual scaffolding. Likewise, students' English proficiency levels did not eventually have any influence on the LREs, which resulted in better revision outcomes. Additionally, peer interaction provides students with valuable experiences in the social dimension, and the writing process helps advocate students' perception in producing their writing. Especially, it also develops their affective strategy and reinforces their critical thinking skills, 
as well as enhances their social interaction ability. Thus, peer feedback supports a student-centered method and learner autonomy for the students.

With regards to the implications, a crucial issue of this study is related to the EFL students with a common language and culture; therefore, the research put emphasis on the intensive peer feedback training. However, although there was still some hardship in conducting the research, providing feedback by peers had fruitful benefits in both the pedagogic and theoretical results, which could be used in the relevant fields of language teaching such as writing and speaking skills. For instance, the process writing theory offers theoretical support for conducting peer feedback whereas pedagogic implementations of using peer feedback in a writing classroom can be applied. Additionally, the collaborative learning theory could be incorporated into a framework in order to investigate the issues of peer feedback such as peer interaction, collaborative learning, student motives, and stances with clear pedagogy. Consequently, peer feedback should be implemented in L2 writing classroom.

\section{References}

Ahmadain, M \& Tajabadi, A. (2017). Patterns of interaction in young EFL learners' pair work: The relationship between pair dynamics and vocabulary acquisition. The Southeast Asian Journal of English Language Studies, 22(3), 98-114. https://doi.org/10.17576/3L-2017-2301-08

Allharbi, M.A. (2019). Patterns of EFL learners' and instructor's interactions in asynchronous group discussion on free writing. Arab Society of English Language Studies. https://doi.org/10.28945/4143

Berkenkotter, C., \& Huckin, T. (1995). Genre knowledge in disciplinary communication: Cognition/ culture/power. Hillsdale, NJ: Lawrence Erlbaum. https://doi.org/10.2307/358302

Brusa, M \& Harutyunyan, L. (2019). Peer review: A tool to enhance the quality of academic written productions. English Language Teaching, 12(5). https://doi.org/10.5539/elt.v12n5p30

Chang, C. Y.-h. (2016). Two decades of research in L2 peer review. Journal of Writing Research, 8(1), 81-117. https://doi.org/10.17239/jowr-2016.08.01.03

Creswell, J. W. (2012). Educational research: Planning, conducting, and evaluating quantitative and qualitative research (4th ed.). Boston, MA: Pearson Education Inc.

Farrah, M. (2012). The impact of peer feedback on improving the writing skills among Hebron University students. An-Najah University Journal for Research, 26(1), 179-210

Ferris, D. R. (2003). Response to Student Writing. Mahwah, N.J.: Lawrence Erlbaum Associates, Inc.

Flower, L. S., \& Hayes, J. R. (1981). A cognitive process theory of writing. College Composition and Communication, 32, 365-387. https://doi.org/10.2307/356600

Grabe, W. \& Kaplan, R.B. (1996). Theory \& practice of writing. New York: Longman.

Halliday, M. A. K. (1978). Language as a social semiotic: The social interpretation of language and meaning. London: Edward Arnold.

Hirose, K. (2008). Cooperative learning in English writing instruction through peer feedback. Retrieved from: jasce.jp/conf05/hirosepaper.doc.

Hu, G. \& S. T. E. Lam. (2010). Issues of cultural appropriateness and pedagogical efficacy: Exploring peer review in a second language writing class. Instructional Science, 38, 371-394. https://doi.org/10.1007/s11251-008-9086-1

Hyland, K., \& Hyland, F. (2006). Feedback on second language students' writing: Contexts and Issues. New York: Cambridge University Press. https://doi.org/10.1017/CBO9781139524742

Jin, L., \& Zhu, W. (2010). Dynamic motives in ESL computer-mediated peer response. Computers and Composition, 27(4), 284-303. https://doi.org/10.1016/j.compcom.2010.09.001

Khalil, E. (2018). The efficacy of peer feedback in Turkish EFL students' writing performance: Journal of Literature and Art Studies, 8(6), 920-931. https://doi.org/10.17265/2159-5836/2018.06.011

Kim, M. (2005). Peer Assessment as a Learning Method. The Effects of the Assessor and Assessee's Role on Metacognitive Awareness, Performance, and Attitude in a Technology-Related Design Task. Ph.D. dissertation, The Florida State University.

Kunwongse, S. (2013). Peer Feedback, Benefits and Drawbacks. Thammasat Review, Special Issue. 
Lam, R. (2010). A peer review training workshop: Coaching students to give and evaluate peer feedback. TESL Canada Journal, 27(2), 114 - 127. https://doi.org/10.18806/tesl.v27i2.1052

Lee, I. (2008). Understanding teachers' written feedback practices in Hong Kong secondary classrooms. Journal of Second Language Writing, 17, 69-85. https://doi.org/10.1016/j.jslw.2007.10.001

Leeser, M.J. (2004). Learner proficiency and focus on form during collaborative dialogue. Language Teaching Research, 8, 55-81. https://doi.org/10.1191/1362168804lr134oa

Lei, Z. (2017). Salience of student written feedback by peer-revision in EFL writing class. English Language Teaching, 10(12), 151-157. https://doi.org/10.5539/elt.v10n12p151

Liu, N., \& D. Carless. (2006). Peer Feedback: The Learning Element of Peer Assessment. Teaching in Higher Education, 11(3), 279-290. https://doi.org/10.1080/13562510600680582

Liu, J. \& Hansen. J. (2002). Peer response in second language writing classrooms. Michigan: University of Michigan Press. https://doi.org/10.3998/mpub.8952

Mangelsdorf, K. (1992). Peer reviews in the ESL composition classroom: What do the students Think?. ELT Journal, 46(3), 274-283. https://doi.org/10.1093/elt/46.3.274

Min, H. T. (2005). Training students to become successful peer reviewers. System, 33(2), 293-308. https://doi.org/10.1016/j.system.2004.11.003

Min, H.-T. (2016). Effect of teacher modeling and feedback on EFL students' peer review skills in peer review training. Journal of Second Language Writing, 31, 43-57. https://doi.org/10.1016/j.jslw.2016.01.004

Nguyen, H, T. (2016). Peer Feedback Practice in EFL Tertiary Writing Classes. English Language Teaching, 9(6), 76-91. https://doi.org/10.5539/elt.v9n6p76

Ohta, A. (2000b). Rethinking recasts: A learner-centered examination of corrective feedback in the Japanese classroom. In J. K. Hall \& L. Verplaetse (Eds.), The Construction of second and foreign language learning through classroom interaction (pp. 47-71). Mahwah, NJ: Erlbaum.

Paltridge, B. (2004). The exegesis as a genre: An ethnographic examination. In L. Ravelli \& R. Ellis (Eds.). Analysing academic writing: Contextualized frameworks (pp. 84-103). London: Continuum.

Roberson, A. P. (2014). Patterns of interaction in peer response: the relationship between pair dynamics and revision outcomes. Unpublished dissertation, Georgia State University.

Rollinson, P. (2005). Using peer feedback in the ESL writing class. ELT Journal, 59(1), 23-30. https://doi.org/10.1093/elt/cci003

Rovinelli, R. J., \& Hambleton, R. K. (1977). On the use of content specialists in the assessment of criterion-referenced test item validity. Dutch Journal of Educational Research, 2, 49-60.

Sawaya, Y., \& Yokoyama, Y. (2013). The role of L2 learners' writing ability in peer review sessions from the perspectives of a reviewer and a writer. Annual Review of English Language Education in Japan, 24, 235-249.

Storch, N. (2002). Patterns of interaction in ESL pair work. Language Learning, 52(1), 119-158. https://doi.org/10.1111/1467-9922.00179

Storch, N. (2004). Using activity theory to explain differences in patterns of dyadic interactions in an ESL class. The Canadian Modern Language Review, 60, 457-480. https://doi.org/10.3138/cmlr.60.4.457

Storch, N. (2007). Investigating the merits of pair work on a text-editing task in ESL classes. Language Teaching Research, 11(2), 143-159. https://doi.org/10.1177/1362168807074600

Storch, N \& Aldosari. A. (2013). Pairing learners in pair work activity. Language Teaching Research, 17(1), 1-18. https://doi.org/10.1177/1362168812457530

Swain, M. (2000). The Output Hypothesis and Beyond: Mediating Acquisition through Collaborative Dialogue. In J. P. Lantolf (Ed.), sociocultural theory and second language learning (pp. 97-114). Oxford: Oxford University Press.

Swain, M., Brooks, L. \& Tocalli-Beller, A. (2002). Peer-peer dialogue as a means of second language learning. Annual Review of Applied Linguistics, 22(1), 171-185. https://doi.org/10.1017/S0267190502000090 
Swain, M., \& Lapkin, S. (2002). Talking it through: Two French immersion learners' response to reformulation. International Journal of Educational Research, 37(3-4), 285-304. https://doi.org/10.1016/S0883-0355(03)00006-5

Swain \& Watanabe. (2013). Language: Collaborative Dialogue as a Source of Second Language Learning: The Encyclopedia of Applied Linguistics, Blackwell Publishing Ltd. https://doi.org/10.1002/9781405198431.wbeal0664

Tsui, A. B. M., \& Ng, M. (2000). Do secondary L2 writers benefit from peer comments? Journal of Second Language Writing, 9(2), 147-170. https://doi.org/10.1016/S1060-3743(00)00022-9

Vygotsky, L. S. (1978). Mind in society: the development of higher psychological processes. Cambridge, MA: Harvard University Press.

Watanabe, Y., \& Swain, M. (2007). Effects of proficiency differences and patterns of pair interaction on second language learning: Collaborative dialogue between adult ESL learners. Language Teaching Research, 11(2), 121-142. https://doi.org/10.1177/136216880607074599

White, R., \& Arndt, V. (1991). Process writing. London: Longman.

Yu, S \& Lee, I. (2016). Peer feedback in second language writing (2005-2014). Lang. Teach, 49.4, 461-493. Cambridge University Press. https://doi.org/10.1017/S0261444816000161

Zarei \& Toluei. (2017). Patterns of pair interaction in EFL Dyadic Talk: A Study of Peer Responses. Applied Research on English Language, 6(3), 291-318.

Zheng, C. (2012). Understanding the learning process of peer feedback activity: An ethnographic study of exploratory practice. Language Teaching Research, 16(1), 109-126. https://doi.org/10.1177/1362168811426248

Zhu, W.\& D. Mitchell. (2012) Participation in peer response activity: An examination of peer response stances from an activity theory perspective. TESOL Quarterly, 46(2), 362-386. https://doi.org/10.1002/tesq.22

\section{Appendix A}

The following transcription symbols were adapted from Storch's (2002) study in transcribing peers' dialogues.

\begin{tabular}{ll}
\hline Symbols & \multicolumn{1}{c}{ Meanings } \\
\hline ( ) & Nonverbal sounds, e.g., (laugh) \\
Italics & Word/s pronounced with emphasis \\
$\ldots$ & Short pause, between 0.5 and 3 seconds \\
{$[5]$} & Longer pause; the number in the square brackets indicates the \\
& length of the pause in seconds \\
{[} & Beginning of simultaneous/overlapping talk, end of overlapping \\
& talk is indicated by ] \\
$?$ & An exclamation mark denotes a sharp rise at the end of a word or phrase \\
S-O & A question mark denotes rising intonation at the end of a word or phrase \\
$(())$ & The speaker is spelling out \\
& Comments made by the researcher to describe other phenomena, e.g., \\
& $($ (writing))
\end{tabular}

